\title{
Novel bioemulsifier produced by a Paenibacillus strain isolated from crude oil
}

\author{
Eduardo J Gudiña', Jorge FB Pereira², Rita Costa², Dmitry V Evtuguin² ${ }^{2}$ João AP Coutinho², José A Teixeira ${ }^{1}$ \\ and Lígia R Rodrigues ${ }^{1 *}$
}

\begin{abstract}
Background: Surface active compounds produced by microorganisms are attracting a pronounced interest due to their potential advantages over their synthetic counterparts, and to the fact that they could replace some of the synthetics in many environmental and industrial applications.

Results: Bioemulsifier production by a Paenibacillus sp. strain isolated from crude oil was studied. The bioemulsifier was produced using sucrose with and without adding hydrocarbons (paraffin or crude oil) under aerobic and anaerobic conditions at $40^{\circ} \mathrm{C}$. It formed stable emulsions with several hydrocarbons and its emulsifying ability was not affected by exposure to high salinities (up to $300 \mathrm{~g} / \mathrm{l})$, high temperatures $\left(100^{\circ} \mathrm{C}-121^{\circ} \mathrm{C}\right.$ ) or a wide range of pH values (2-13). In addition, it presented low toxicity and high biodegradability when compared with chemical surfactants. A preliminary chemical characterization by Fourier Transform Infrared Spectroscopy (FT-IR), proton and carbon nuclear magnetic resonance ( ${ }^{1} \mathrm{H}$ NMR and ${ }^{13} \mathrm{C}$ CP-MAS NMR) and size exclusion chromatography indicated that the bioemulsifier is a low molecular weight oligosaccharide-lipid complex.

Conclusion: The production of a low molecular weight bioemulsifier by a novel Paenibacillus strain isolated from crude oil was reported. To the best of our knowledge, bioemulsifier production by Paenibacillus strains has not been previously reported. The features of this novel bioemulsifier make it an interesting biotechnological product for many environmental and industrial applications.
\end{abstract}

Keywords: Surface active compound, Bioemulsifier, Paenibacillus sp, Bioremediation

\section{Background}

Microbial surface-active compounds (SACs) are amphiphilic metabolites consisting of hydrophobic and hydrophilic moieties which allow them to partition at the interface between fluid phases with different degrees of polarity. These compounds comprise a wide variety of structures, and can be divided into two main groups: low molecular weight and high molecular weight SACs. Low molecular weight molecules reduce surface and interfacial tension as their primary activity. They include lipopeptides and glycolipids among others, and their molecular masses range from 500 to $1500 \mathrm{Da}$ [1]. On the other hand, high molecular weight polymers, so-called bioemulsifiers, are more effective in forming and stabilizing oil in water or water in oil

\footnotetext{
*Correspondence: Irmr@deb.uminho.pt

${ }^{1}$ CEB - Centre of Biological Engineering, University of Minho, 4710-057 Braga, Portugal

Full list of author information is available at the end of the article
}

emulsions, but do not necessarily reduce surface or interfacial tension. Usually they consist of polymeric structures including polysaccharides, proteins, lipids and complexes of these molecules. Although less studied than biosurfactants, bioemulsifiers production has also been described in different bacteria [2-11], yeasts [12-15] and filamentous fungi [16]. Bioemulsifiers exhibit similar or better emulsifying activities when compared with their chemical counterparts, and because of their biological origin, they are considered less toxic and more easily biodegradable, thus implying a greater environmental compatibility $[8,17,18]$.

Bioemulsifiers, due to their properties, could replace some of the chemically synthesized emulsifiers in bioremediation, enhanced oil recovery, clean-up of oil contaminated pipes and vessels, as additives in cleaning products and laundry formulations, and as emulsion- 
stabilizing agents in the food, cosmetic or pharmaceutical industries $[5,6,8,10,13,15,16,19,20]$. For instance, numerous patents have been issued claiming the application of bioemulsifiers produced by members of the genus Acinetobacter in bioremediation, in the petroleum industry, or as additives in personal care products, paints, dyes and cosmetics, among others (reviewed by Shete et al. [21]).

Despite their potential applications, the large-scale production of bioemulsifiers has not been achieved due to their high production costs. While high production costs can be tolerated for compounds used at low concentrations in highly-priced products, such as cosmetics, they are unaffordable for applications that require high volumes of low-priced compounds. One of the advantages of bioemulsifiers when compared with the synthetic emulsifiers, for applications such as bioremediation, is that they can be produced in situ by selected microorganisms using inexpensive substrates, which constitutes a cheaper option than the addition of a purified compound. The development of new and cheaper processes, the use of low-cost raw materials and the isolation of new microorganisms capable of producing bioemulsifiers in an efficient manner can reduce their production costs and increase their competitiveness $[1,22]$.

The aim of this work was to study the bioemulsifier production by a new isolate obtained from crude oil. The preliminary chemical structure of the bioemulsifier and its functional properties were studied. Furthermore, its toxicity and degradability were evaluated.

\section{Results and discussion}

Characterization of the bioemulsifier-producing strain

The isolate \#510 was identified according to the partial sequence obtained from its $16 \mathrm{~S}$ rRNA gene. The 1451 bp sequence obtained was compared with those deposited at the NCBI database, and revealed the highest similarity (99\%) with different species belonging to the genus Paenibacillus (Figure 1). According to the results, the isolate was designated as Paenibacillus sp. \#510. The partial sequence of the $16 \mathrm{~S}$ rRNA gene was deposited in the GenBank database under accession number KF151179. The strain was deposited on Micoteca da Universidade do Minho (MUM) culture collection under the reference number MUM 14.03.

\section{Effect of aeration and hydrocarbons on bioemulsifier production}

Paenibacillus sp. \#510 was found to produce an extracellular emulsifying agent (bioemulsifier). The bioemulsifier production was studied using MSS medium (with and without sucrose) supplemented with paraffin $(5 \% \mathrm{w} / \mathrm{v})$ or crude oil $(5 \% \mathrm{w} / \mathrm{v})$ under aerobic and anaerobic conditions. The results obtained are shown in Table 1.

The use of paraffin or crude oil as sole carbon sources yielded no growth. However, the addition of paraffin or crude oil to the culture medium containing sucrose resulted in emulsification values higher than those obtained without hydrocarbons, both under aerobic and anaerobic conditions (Table 1). Therefore, both hydrocarbons induced the bioemulsifier production by Paenibacillus sp. \#510. The best emulsifying activity

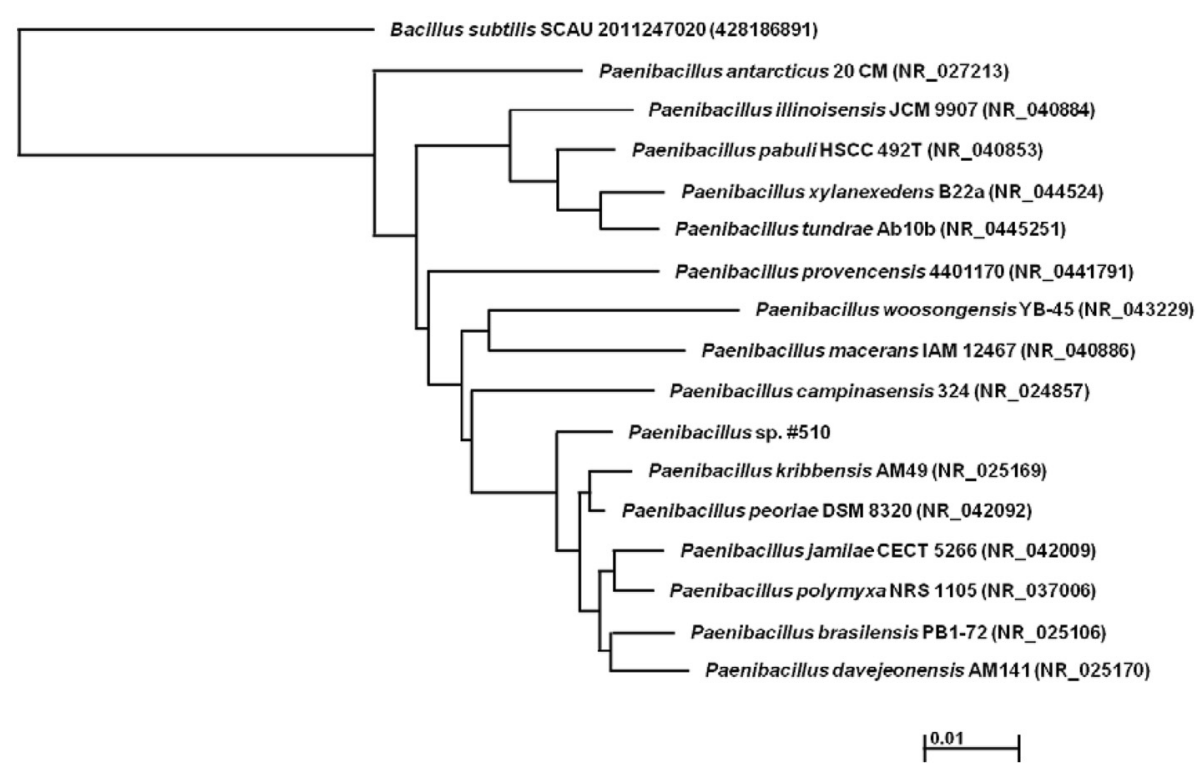

Figure 1 Phylogenetic neighbor-joining tree based on the 16S rRNA sequence of Paenibacillus sp. \#510. 
Table 1 Effect of aeration and hydrocarbons on bioemulsifier production

\begin{tabular}{lccll}
\hline Medium & ST (mN/m) & $\mathbf{E}_{24}(\%)$ & $\begin{array}{l}\text { [Emulsifier] } \\
(\mathbf{g} / \mathbf{l})\end{array}$ & $\begin{array}{l}\text { [Biomass] } \\
(\mathbf{g} / \mathbf{l})\end{array}$ \\
\hline \multicolumn{2}{l}{ Anaerobic (120 rpm) } & & & \\
MSS & $52.9 \pm 1.5$ & $36.4 \pm 4.4$ & $5.0 \pm 0.5$ & $0.437 \pm 0.086$ \\
MSS + Paraffin & $51.1 \pm 1.8$ & $43.1 \pm 3.1$ & $5.6 \pm 0.2$ & $0.523 \pm 0.043$ \\
MSS + Crude Oil & $50.6 \pm 1.4$ & $42.1 \pm 2.1$ & $5.4 \pm 0.4$ & $0.496 \pm 0.091$ \\
Aerobic (120 rpm) & & & \\
MSS & $51.1 \pm 0.9$ & $49.9 \pm 2.7$ & $6.1 \pm 0.2$ & $0.846 \pm 0.112$ \\
MSS + Paraffin & $50.1 \pm 1.6$ & $64.4 \pm 1.6$ & $7.9 \pm 0.1$ & $0.904 \pm 0.099$ \\
MSS + Crude Oil & $50.0 \pm 0.6$ & $62.1 \pm 2.5$ & $7.4 \pm 0.3$ & $0.885 \pm 0.121$ \\
\hline
\end{tabular}

Surface tension values $(\mathrm{mN} / \mathrm{m})$, emulsifying activity $\left(\mathrm{E}_{24}, \%\right)$ and biomass and bioemulsifier concentrations ( $\mathrm{g} / \mathrm{l}$ ) obtained with Paenibacillus sp. \#510 grown at $40^{\circ} \mathrm{C}$ under aerobic (7 days) and anaerobic (10 days) conditions in MSS and MSS supplemented with paraffin $(5 \% \mathrm{w} / \mathrm{v})$ or crude oil $(5 \% \mathrm{w} / \mathrm{v})$. The emulsifying indexes were performed using $n$-hexadecane. The surface tension and the emulsifying activity of MSS medium were $70.3 \pm 0.4 \mathrm{mN} / \mathrm{m}$ and $0.0 \%$, respectively. Results represent the average of three independent experiments \pm standard deviation.

against $n$-hexadecane $(64.4 \pm 1.6 \%)$ was obtained when Paenibacillus sp. \#510 was grown under aerobic conditions and in the presence of paraffin. This activity was in accordance with data reported for other bioemulsifierproducing microorganisms $[8,9,13,20,23]$. Furthermore, the emulsions formed remained stable for one month at $40^{\circ} \mathrm{C}$.

The amount of bioemulsifier produced by Paenibacillus sp. \#510 under aerobic conditions (6.1-7.9 g/l) was similar to those reported for yeasts and Streptomyces species $[13,14,20]$, but considerably higher when compared with the amounts produced by other bacteria (between 1.4 and $4.2 \mathrm{~g} / \mathrm{l})$ [3,5,9,11]. Moreover, the bioemulsifier produced by Paenibacillus sp. \#510 did not significantly reduce the surface tension of the culture medium, which is the general characteristic of bioemulsifiers produced by a number of bacteria, yeasts and filamentous fungi $[4,6,8-12]$.

To our knowledge, bioemulsifier production by Paenibacillus strains has not been previously reported. Najafi et al. [24] isolated a Paenibacillus alvei strain from an Iranian oil field that produced a lipopeptide biosurfactant able to reduce the surface tension up to $35 \mathrm{mN} / \mathrm{m}$. However, no emulsifying activity was reported by the authors for that isolate.

\section{Kinetics of bioemulsifier production}

Figure 2 shows the kinetics of cell growth and bioemulsifier production by Paenibacillus sp. \#510 in MSS and MSS medium supplemented with paraffin under aerobic conditions. Bioemulsifier production was found to be growth-associated in both cases, as a parallel relationship was observed between the biomass production and the emulsifying activity. The same profile was observed for

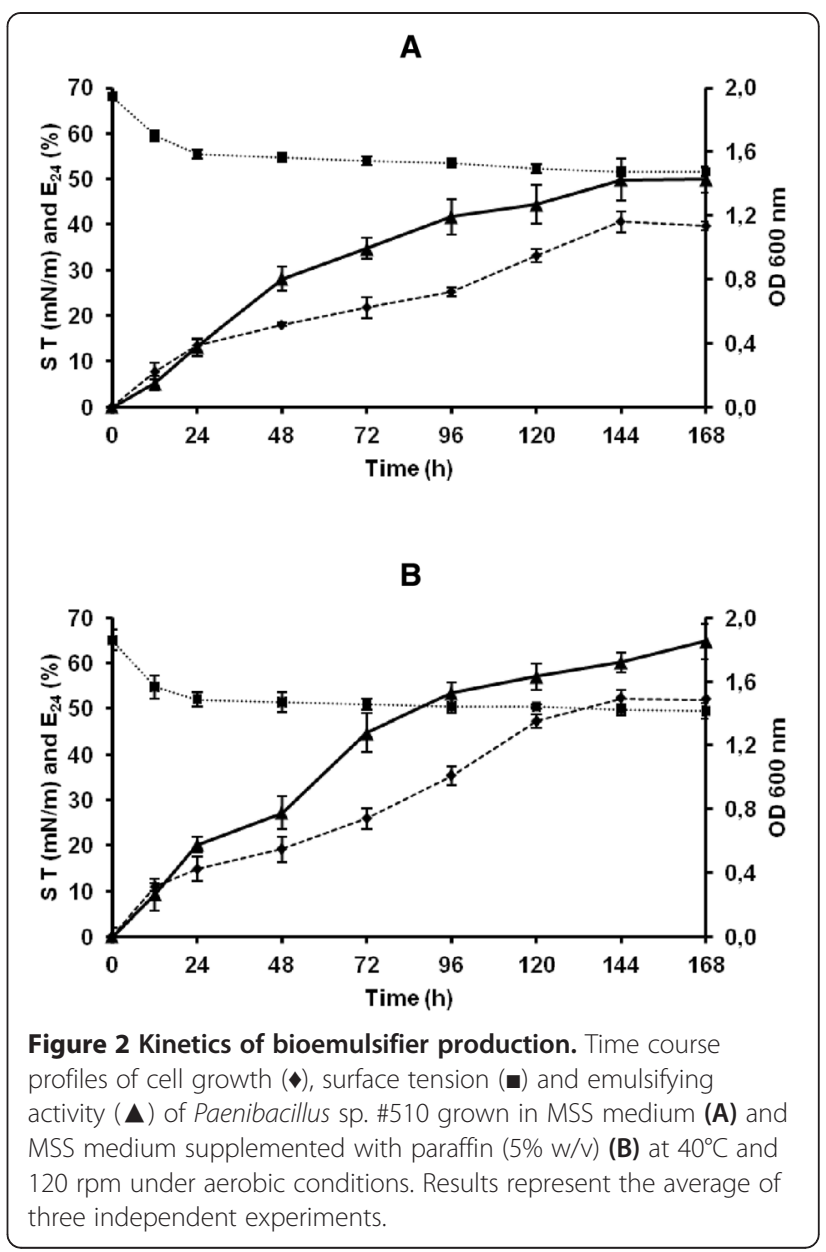

several other bioemulsifier-producing microorganisms $[7,8,20,23]$. However, in other reports, a partially growthassociated bioemulsifier production profile was observed, in which the bioemulsifier production continued during the stationary growth phase [12]. In the current study, cell growth and bioemulsifier production were higher in medium supplemented with paraffin. The highest emulsifying activity was achieved at 168 hours in both media. After that point, the emulsifying activity decreased probably due to the degradation of the bioemulsifier.

\section{Effect of salinity, $\mathrm{pH}$ and temperature on emulsifier stability}

The applicability of SACs in several fields depends on their stability at different temperatures, salinities and $\mathrm{pH}$ values. In order to assess the effect of salinity on the emulsifier activity, bioemulsifier solutions $(1 \mathrm{~g} / \mathrm{l})$ were supplemented with different $\mathrm{NaCl}$ concentrations, ranging from 10 to $300 \mathrm{~g} / \mathrm{l}$, and then emulsifying activity was measured. The addition of $\mathrm{NaCl}$, even in amounts above the limit of saturation $(300 \mathrm{~g} / \mathrm{l})$, did not have a negative effect on the emulsifying activity, which remained almost constant, between 57.5 and 59.0\% (data 
not shown). Bioemulsifiers that are not affected by $\mathrm{NaCl}$ concentrations up to $200-300 \mathrm{~g} / \mathrm{l}$ have been described in bacteria [9], yeasts [12,13] and filamentous fungi [16]. However, in other cases, the emulsifying activity was significantly inhibited at $\mathrm{NaCl}$ concentrations higher than 50-100 g/l [4,11,23,25]. Also, the common chemical surfactants SDS (sodium dodecyl sulfate), Triton X-100 or Tween 80 do not show emulsifying activity at $\mathrm{NaCl}$ concentrations of $100-120 \mathrm{~g} / \mathrm{l}[11,13]$.

The $\mathrm{pH}$ stability of the bioemulsifier was also evaluated. Bioemulsifier solutions $(1 \mathrm{~g} / \mathrm{l})$ were prepared at different $\mathrm{pH}$ values (from 2 to 13 ) and the emulsifying values were measured. The emulsifying activity was almost constant (56.2-59.7\%) over the entire range of $\mathrm{pH}$ values studied (data not shown). Several bioemulsifiers exhibit higher emulsifying activity at acidic [16] or alkaline conditions $[4,9,25]$. In other cases, they are only stable at neutral $\mathrm{pH}$ values [23,27]. Bioemulsifiers produced by some yeasts are also stable in a broad spectrum of $\mathrm{pH}$ values (from 2 to 10 ) $[12,13,19,20]$. Alasan and the bioemulsifier produced by Streptomyces sp. $\mathrm{MC} 1$ are stable at $\mathrm{pH}$ values between 3 and $10[3,20,26]$.

To evaluate the stability of the bioemulsifier at high temperatures, bioemulsifier solutions $(1 \mathrm{~g} / \mathrm{l})$ were exposed to $100^{\circ} \mathrm{C}$ for $1 \mathrm{~h}$, and to $121^{\circ} \mathrm{C}$ for $20 \mathrm{~min}$. Emulsification activity was measured before and after heating, and it was found that the heat treatment did not reduce the emulsion forming capacity of the bioemulsifier against $n$-hexadecane (data not shown). Different bioemulsifiers were shown to remain stable after exposure to $100^{\circ} \mathrm{C}$ for $1 \mathrm{~h}[8,12,13]$ or to $121^{\circ} \mathrm{C}$ for $20 \mathrm{~min}[6,23]$. However, other bioemulsifiers lose some emulsifying capacity at those temperatures $[4,9,16,25,27]$. An exception is alasan, produced by Acinetobacter radioresistens KA53. The activity of this bioemulsifier increases approximately $30 \%$ after incubation at $100^{\circ} \mathrm{C}$ for $10 \mathrm{~min}$, which is accompanied by changes in the conformation of the polysaccharide-protein complex [26].

The high stability of the bioemulsifier herein produced by Paenibacillus sp. \#510 regarding temperature, $\mathrm{pH}$ and salinity clearly demonstrates its potential for applications involving extreme environmental conditions.

\section{Emulsifying activity using different hydrophobic substrates}

The ability to emulsify different hydrocarbons was investigated using a wide range of pure and mixed substrates (Table 2). The bioemulsifier formed stable emulsions with aliphatic ( $n$-hexadecane, $n$-hexane, chloroform, dichloromethane, ethyl acetate) and aromatic (toluene, $x y-$ lene) hydrocarbons, as well as with hydrocarbon mixtures (crude oil, heating oil, paraffin). Gas oil was the only hydrocarbon not efficiently emulsified, whereas crude oil was the best substrate. A broad-spectrum of
Table 2 Emulsifying indexes obtained with different hydrocarbons using the bioemulsifier produced by Paenibacillus sp. \#510

\begin{tabular}{ll}
\hline Hydrocarbon & $\mathbf{E}_{\mathbf{2 4}}(\%)$ \\
\hline Chloroform & $63.8 \pm 0.7$ \\
Crude oil & $75.1 \pm 1.6$ \\
Dichloromethane & $66.1 \pm 1.9$ \\
Ethyl acetate & $52.7 \pm 1.3$ \\
Gas oil & $15.9 \pm 1.2$ \\
Heating oil & $62.7 \pm 1.5$ \\
$\boldsymbol{n}$-hexadecane & $59.3 \pm 1.0$ \\
$\boldsymbol{n}$-hexane & $50.9 \pm 1.8$ \\
Paraffin & $63.1 \pm 1.6$ \\
Toluene & $61.6 \pm 1.1$ \\
Xylene & $59.3 \pm 1.0$
\end{tabular}

Results are expressed as means \pm standard deviations of three independent experiments.

emulsifying activity is essential for the use of a bioemulsifier in industrial processes, such as bioremediation, treatment of industrial effluents, oil tank clean-up, emulsion-facilitated oil transport or emulsion-based fuels, because those processes include different mixtures of hydrophobic compounds. The results herein obtained show that the bioemulsifier produced by Paenibacillus sp. \#510 possesses a high ability to stabilize emulsions with different hydrocarbons, thus representing a potential candidate to be used in a variety of biotechnological and industrial applications. The ability of bioemulsifiers to stabilize emulsions with hydrocarbons of different nature has been described by several authors [3,5,6,11,12,14,23]. However, the other bioemulsifiers reported exhibit considerable substrate specificity. Emulsan does not emulsify pure aliphatic, aromatic or cyclic hydrocarbons; however, mixtures of those compounds can be efficiently emulsified [3]. In other cases, pure hydrocarbons are efficiently emulsified, but the same is not seen for their mixtures [9].

\section{Toxicity tests}

The toxicity of the bioemulsifier produced by Paenibacillus sp. \#510 and three chemical SACs was assessed using Vibrio fisheri as an indicator microorganism. The $\mathrm{EC}_{50}$ values obtained are shown in Table 3. Regarding the bioemulsifier, the results obtained didn't allow calculating the $\mathrm{EC}_{50}$ value. After $30 \mathrm{~min}$ of exposure to the highest bioemulsifier concentration tested $(1000 \mathrm{mg} / \mathrm{l})$, the bioluminescence was reduced by $29 \%$, showing that the bioemulsifier exhibits a low toxicity against $V$. fisheri as compared to the synthetic SACs studied. Furthermore, the results showed that this bioemulsifier exhibits equal or less toxicity when compared with other microbial SACs. In similar assays, Ivshina and co-workers [28] 
Table 3 Toxicity data obtained for the different SACs studied

\begin{tabular}{ll}
\hline Compound & $\mathrm{EC}_{\mathbf{5 0}}(\mathbf{m g} / \mathbf{l})$ \\
\hline Glucopone $^{\oplus} \mathbf{6 5 0}$ & $4.9 \pm 1.3$ \\
Findet $^{\oplus} \mathbf{1 2 1 4} \mathbf{~ N / 2 3}$ & $9.6 \pm 6.2$ \\
LAS & $21.1 \pm 4.8$ \\
Bioemulsifier & N.D. \\
\hline
\end{tabular}

Effective concentration $\left(\mathrm{EC}_{50}\right.$ ) values obtained against Vibrio fisheri (after 30 min of exposure) for the three chemical SACs and the bioemulsifier produced by Paenibacillus sp. \#510. Results are expressed as means \pm standard deviations of three independent experiments. ND: not determined.

reported $\mathrm{EC}_{50}$ values for SACs produced by Rhodococcus spp. and Pseudomonas aeruginosa strains between 50 and $650 \mathrm{mg} / \mathrm{l}$. Moreover, Lima et al. [29] reported $\mathrm{EC}_{20}$ values for different microbial SACs (including lipopeptides, glycolipids and flavolipids) between 261 and $736 \mathrm{mg} / \mathrm{l}$, higher than the obtained for SDS, $25 \mathrm{mg} / \mathrm{l}$. Franzetti and collaborators [8] also reported a low toxicity for the bioemulsifier produced by Variovorax paradoxus 7bCT5 against $V$. fisheri, with an inhibition of $34 \pm 2 \%$ after 15 min of exposure to the highest concentration tested $(500 \mathrm{mg} / \mathrm{l})$.

\section{Biodegradability tests}

Biodegradability is an important feature when evaluating the environmental risk associated with the use of SACs. Microbial SACs are generally considered to be less toxic and more biodegradable than synthetic SACs. However, these properties are sometimes assumed as a direct consequence of their natural origin without further studies, and data available in the literature on their biodegradation is scarce $[8,30]$.

The biodegradability of the chemical SACs and the bioemulsifier produced by Paenibacillus sp. \#510 was assessed by liquid respirometric assays. COD and BOD provide information on the amount of oxygen necessary to degrade a compound through chemical or biological pathways, respectively.

COD values determined for Glucopone 650 , Fin$\operatorname{det}^{\oplus} 1214 \mathrm{~N} / 23$ and LAS were $335.5 \pm 0.5,384.5 \pm 3.5$ and $345.5 \pm 0.5 \mathrm{mg} \mathrm{O} / \mathrm{l}$, respectively; in contrast with the value obtained for the bioemulsifier, $10.9 \pm 0.2 \mathrm{mg} \mathrm{O}_{2} / \mathrm{l}$. Regarding the $\mathrm{BOD}_{5}$, for the three chemical surfactants, the value obtained was around $35 \mathrm{mg} \mathrm{O} / \mathrm{l}$, whereas in the case of the bioemulsifier that value was $9.5 \pm 2.0 \mathrm{mg}$ $\mathrm{O}_{2} / 1$. The lower COD and $\mathrm{BOD}_{5}$ values obtained for this bioemulsifier when compared with the chemical SACs indicate that it is more easily biodegradable.

The ratio $\mathrm{BOD}_{5} / \mathrm{COD}$ gives an indication of the biodegradability of a given compound. Ratios higher than 0.4-0.6 suggest that the compound can be easily degraded by microorganisms. For the chemical SACs tested, the ratios obtained were around 0.1, thus demonstrating that they have a low biodegradability. Regarding the bioemulsifier, the ratio obtained (0.9) indicates an easier biodegradation.

Franzetti et al. [8] reported $\mathrm{BOD}_{5} / \mathrm{COD}$ ratios for the bioemulsifier produced by $V$. paradoxus $7 \mathrm{bCT} 5$ between 0.24 and 0.30 , showing a moderate biodegradability by soil bacteria. Lima and co-workers [30] reported a higher biodegradability of different biosurfactants (including glycolipids, lipopeptides and flavolipids) when compared with the chemical surfactant SDS using pure and mixed bacterial cultures. Also, Mohan et al. [31] reported a higher biodegradability of rhamnolipids comparing with Triton X-100. The degradation of rhamnolipids by a bacterial consortium isolated from a soil sample under aerobic and nitrate-reducing conditions was also reported by Chrzanowski et al. [32]. Frank and co-workers [33] showed that a bacterial inoculum obtained from a soil sample was able to use different SACs (rhamnolipids, sophorolipids, trehalose tetraester and Tween 80) as sole carbon and energy source, but only rhamnolipids were completely degraded, whereas Tween 80 simply suffered a primary degradation. Biodegradability and toxicity are important features when evaluating the environmental risk associated with the use of SACs. It is often assumed that microbial SACs are more suitable for different applications than the synthetic surfactants due to their lower toxicity and higher biodegradability. Regarding the bioemulsifier produced by Paenibacillus sp. \#510, toxicity data coupled with $\mathrm{BOD}_{5} / \mathrm{COD}$ ratios indicate that it is a greener option when compared with the synthetic surfactants studied.

\section{Preliminary chemical characterization FT-IR analysis}

Firstly, a rough characterization of the bioemulsifier was performed by FT-IR analysis (Figure 3). The spectrum obtained clearly showed the characteristic bands belonging to carbohydrates, specifically $\mathrm{O}-\mathrm{H}$ stretching at ca. $3400 \mathrm{~cm}^{-1}$ (e.g. 3375 and $3442 \mathrm{~cm}^{-1}$ ); and a set of intense bands between 1138 and $1000 \mathrm{~cm}^{-1}(1138,1122$ and $1066 \mathrm{~cm}^{-1}$ ) assigned to $\mathrm{C}-\mathrm{O}-\mathrm{C}$ anti-symmetric bridge stretching [34,35]. The peak at $1066 \mathrm{~cm}^{-1}$ can also be related to the $\mathrm{C}-\mathrm{OH}$ stretching and the peak at $1122 \mathrm{~cm}^{-1}$ to primary $\mathrm{C}-\mathrm{OH}$ group at the $\mathrm{C} 6$ position. On the other hand, it was also observed the presence of some characteristic bands of fatty acids, namely the band at $2929 \mathrm{~cm}^{-1}$ assigned to $\mathrm{C}-\mathrm{H}$ stretching; and the relatively intense band at $1707 \mathrm{~cm}^{-1}$ assigned to $\mathrm{C}=\mathrm{O}$ in non-conjugated fatty acids. A stretching vibration of a carboxylate ion in eventual uronic moieties of carbohydrates or in fatty acids at ca. $1650 \mathrm{~cm}^{-1}$ was also detected. 


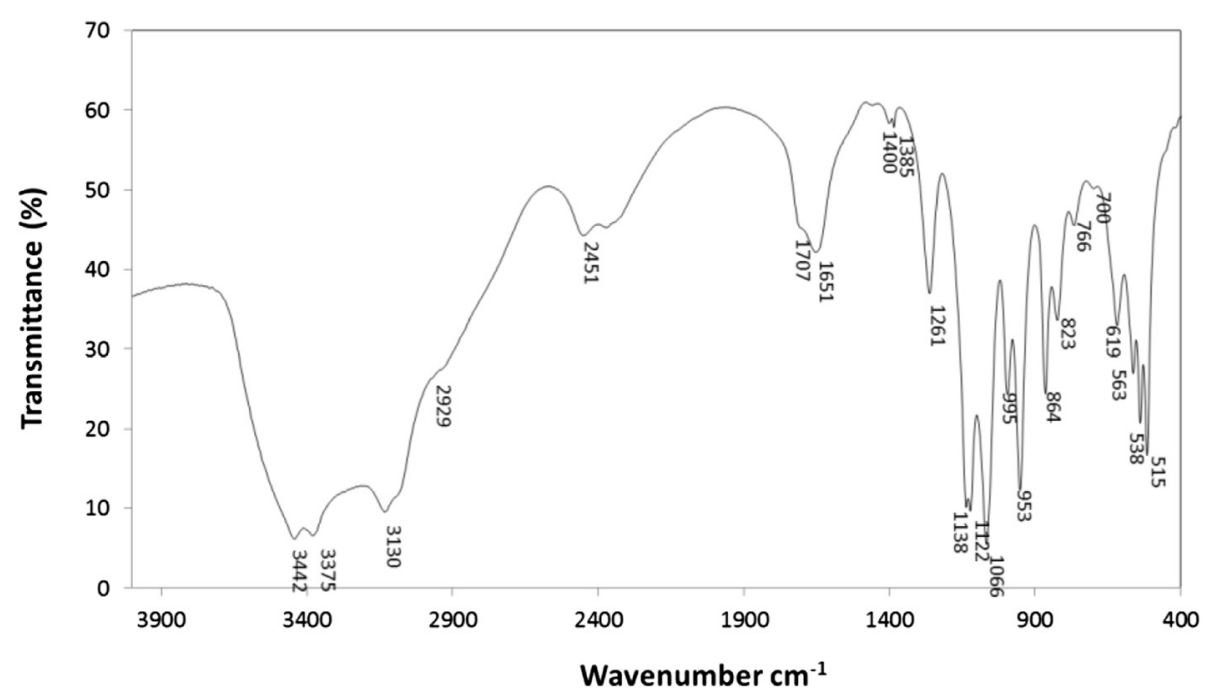

Figure 3 FT-IR spectrum for bioemulsifier extract produced by Paenibacillus sp. \#510.

\section{SEC analysis}

The SEC analysis of the water soluble fraction of the bioemulsifier showed fairly narrow molecular weight distribution with rather low average molecular weight $(\mathrm{Mw})$ of ca. 1000 Da obtained using pullulan calibration standards. Hence, the bioemulsifier should contain mono-dispersed oligosaccharides. The preliminary qualitative sugars analysis carried out by acid methanolysis revealed the presence of glucose as the major constituent of water-soluble oligosaccharides. Further evidence for the presence of oligosaccharides in the composition of the bioemulsifier was obtained using ${ }^{13} \mathrm{C}$ CP-MAS NMR and ${ }^{1} \mathrm{H}$ NMR analysis.

\section{${ }^{13} \mathrm{C}$ CP-MAS NMR and ${ }^{1} \mathrm{H}$ NMR spectroscopy}

${ }^{13} \mathrm{C}$ CP-MAS NMR spectrum of the bioemulsifier suggests its eventual amphiphilic character. The strong resonances at 10-50 ppm assigned to aliphatic $\mathrm{CH}_{3}$ / $\mathrm{CH}_{2} / \mathrm{CH}$ moieties, and a group of resonances centered at ca $176 \mathrm{ppm}$ assigned to carbon of carboxylic groups [36,37], indicate an eventual major contribution of fatty acids (Figure 4A). At least part of these fatty acids should be hydroxylated as follows from the relatively intensive resonance at ca. $55 \mathrm{ppm}$ assigned to the aliphatic carbon linked to the hydroxyl group. A series of resonances at $60-110 \mathrm{ppm}$ may be assigned to oligosaccharides (Figure 4A). Thus, the resonances at 98-108 ppm are typical of glycosidic carbons (C1), and the resonances at $60-80 \mathrm{ppm}$ of primary/secondary carbons (C2-C6) in pentosans and hexosans [37].

The presence of characteristic aliphatic and hydroxyl groups in the oligosaccharide-lipid complex was also confirmed by ${ }^{1} \mathrm{H}$ NMR spectrum (Figure $4 \mathrm{~B}$ ). Noteworthy, only the chloroform-soluble counterpart of the bioemulsifier was analysed in this case. The ${ }^{1} \mathrm{H}$ NMR spectrum of the bioemulsifier showed the presence of $\mathrm{CH}_{3}, \mathrm{CH}_{2}$, and $\mathrm{CH}$ groups as revealed from the resonances at 0.6-2.0 ppm, and the presence of $>\mathrm{CH}-\mathrm{OH}$ moieties was evidenced from proton signals at 3.5-4.0 ppm [38]. At least part of the detected $>\mathrm{CH}-\mathrm{OH}$ moieties may belong also to chemically bonded carbohydrates.

According to this preliminary chemical characterization, it seems that the bioemulsifier produced by Paenibacillus sp. \#510 is a low molecular weight oligosaccharide-lipid complex in which the fatty acids and oligosaccharides could be structurally associated involving either covalent or non-covalent bonds. Therefore, further studies using advanced wet chemistry, NMR and mass spectrometry will be necessary to fully elucidate its structure.

Several species belonging to the genus Acinetobacter produce extracellular bioemulsifiers, with molecular weights around $1000 \mathrm{kDa}$. Emulsan, produced by Acinetobacter venetianus RAG-1, is a non-covalently linked complex of a lipoheteropolysaccharide and a protein. The polysaccharide (apo-emulsan) is composed mainly of D-galactosamine, D-galactosaminuronic acid and diamino-dideoxy glucosamine [2]. Surface activity of emulsan is largely due to the presence of long chain fatty acids, which are covalently linked to the polysaccharide backbone. The protein associated with the polysaccharide promotes the emulsifying activity [39]. Alasan consists of an anionic heteropolysaccharide containing covalently bound alanine and proteins [3]. The proteins are the active component of the emulsifier, and the purified polysaccharide (apo-alasan) shows very low emulsifying activity. Three proteins with molecular weights of 16, 31 and $45 \mathrm{KDa}$ were isolated, which showed higher emulsifying activity compared to the 

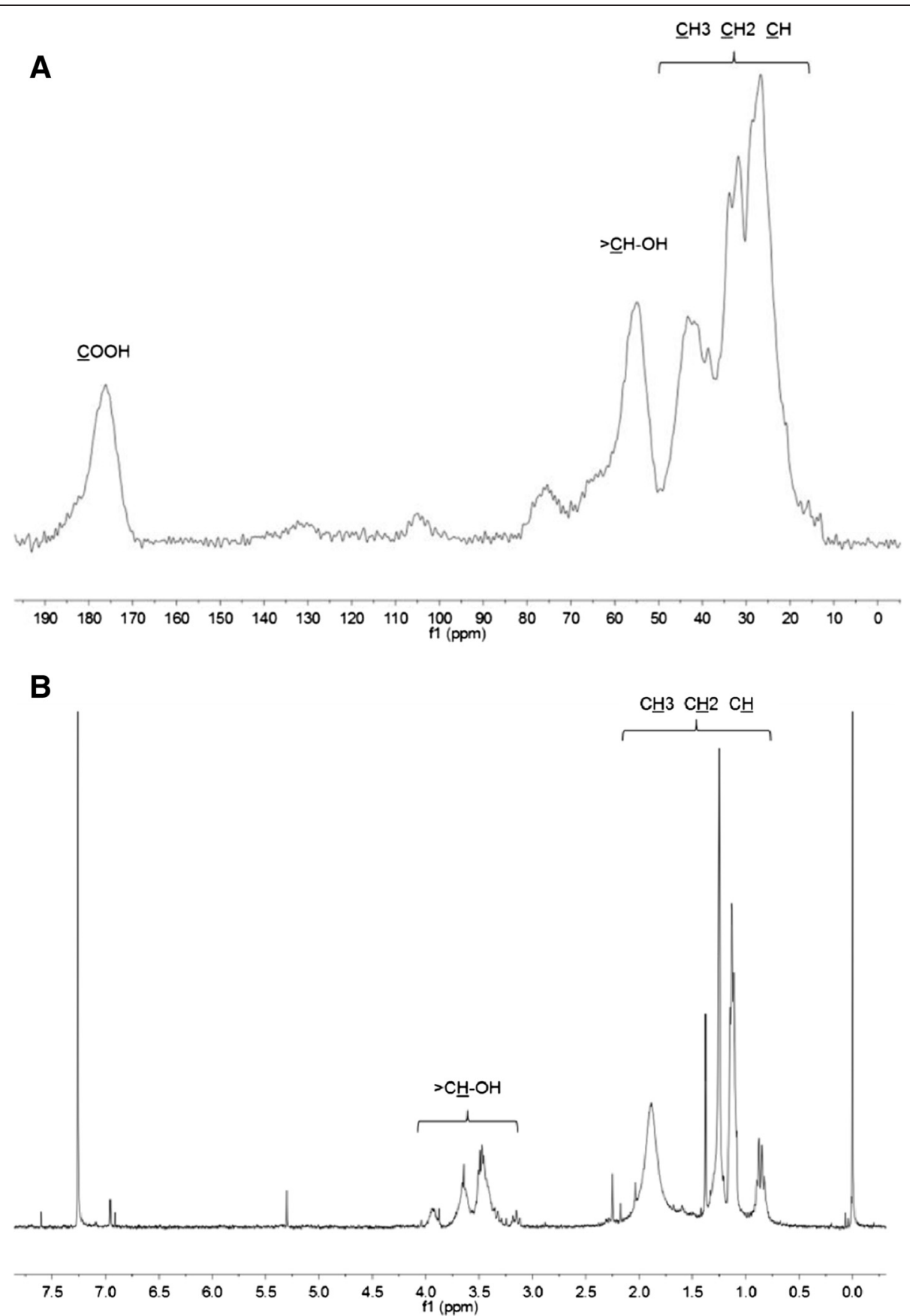

Figure 4 Nuclear Magnetic Resonance spectra of the bioemulsifier produced by Paenibacillus sp. \#510. ${ }^{13} \mathrm{C}$ CP-MAS NMR spectrum (A) and ${ }^{1} \mathrm{H}$ NMR spectrum (B).

apo-alasan, especially the $45 \mathrm{KDa}$ protein, but the emulsion formed was considerably less stable than that produced by the entire molecule [26]. Acinetobacter calcoaceticus BD4 produces a bioemulsifier called BD4. emulsan. This strain produces a large anionic polysaccharide capsule composed of a repeating heptasaccharide unit containing L-rhamnose, D-glucose, D-glucuronic acid and D-mannose in molar ratios of 4:1:1:1. Under certain growth conditions, the capsule (hydrophilic) is released together with the bound protein (hydrophobic) into the medium, forming a complex with high emulsifying activity. The purified protein and the polysaccharide itself do not show emulsifying activity. However, the original emulsifying activity can be reconstituted by mixing both fractions [40]. Furthermore, as previously mentioned different bacteria, yeasts and filamentous 
fungi produce extracellular bioemulsifiers with different compositions (Table 4). However, all these compounds are high molecular weight bioemulsifiers, in contrast with the bioemulsifier produced by Paenibacillus sp. \#510 herein studied.

\section{Conclusions}

In this study, the production of a bioemulsifier by a novel Paenibacillus strain isolated from crude oil was reported. The preliminary chemical characterization revealed that it is a low molecular weight oligosaccharidelipid complex. To our knowledge, the production of a low molecular weight bioemulsifier by a Paenibacillus strain has not been previously reported. The bioemulsifier was found to form stable emulsions with a variety of hydrophobic compounds and was not affected by exposure to extreme environmental conditions. Furthermore, the bioemulsifier exhibited a good environmental compatibility as can be concluded from the toxicity and biodegradability results obtained. Altogether, the features of this novel bioemulsifier make it an interesting biotechnological product for many environmental and industrial applications.

\section{Methods}

\section{Characterization of the bioemulsifier producing strain}

A promising bioemulsifier-producing strain (isolate \#510) was isolated from a crude oil sample obtained from a Brazilian oil field and was identified by $16 \mathrm{~S}$ rRNA sequencing. The 16S rRNA gene was amplified by PCR using primers $\mathrm{fD} 1$ and $\mathrm{rD} 1$. The resulting sequence

Table 4 Composition of bioemulsifiers produced by different bacteria, yeasts and filamentous fungi

\begin{tabular}{|c|c|c|}
\hline & Composition & Microorganism \\
\hline \multirow[t]{10}{*}{ Bacteria } & $C+L+P$ & Aeribacillus pallidus YM-1 [10] \\
\hline & & Geobacillus pallidus XS2 [9] \\
\hline & & Lactobacillus pentosus CECT4023 [41] \\
\hline & & Variovorax paradoxus $7 \mathrm{bCT} 5[8]$ \\
\hline & $C+L$ & Aeromonas spp. [4] \\
\hline & & Rhodococcus sp. TA6 [23] \\
\hline & $C+P$ & Bacillus licheniformis ACO1 [6] \\
\hline & & Streptomyces sp. MC1 [20] \\
\hline & $L+P$ & $\begin{array}{l}\text { Pseudomonas nitroreducens TSB.MJ10 } \\
\text { [11] }\end{array}$ \\
\hline & C & Halomonas eurihalina F2-7 [5] \\
\hline \multirow[t]{3}{*}{ Yeasts } & $C+L+P$ & Yarrowia lipolytica [15] \\
\hline & $C+L$ & Geotrichum sp. [13] \\
\hline & & Trichosporon spp. $[12,14]$ \\
\hline $\begin{array}{l}\text { Filamentous } \\
\text { fungi }\end{array}$ & $C+L+P$ & Penicillium sp. [16] \\
\hline
\end{tabular}

C: carbohydrate; L: lipid; P: protein.
(1451 bp) was compared with sequences in the GenBank database of the National Center for Biotechnology Information (NCBI) (http://www.ncbi.nlm.nih.gov) using the nucleotide-nucleotide blast (BLASTn) network service. Multiple sequence alignments were carried out using ClustalW and a consensus neighbor-joining tree was designed using Molecular Evolutionary Genetics Analysis (MEGA) Software version 5.1. The bioemulsifier production and characterization were performed according to the methodologies described in the following sections.

\section{Effect of culture conditions and hydrocarbons on bioemulsifier production}

MSS medium was used to study the bioemulsifier production. The composition of MSS medium was $(\mathrm{g} / \mathrm{l})$ : $\mathrm{NaCl}$ 10.0; sucrose 10.0; $\mathrm{Na}_{2} \mathrm{HPO}_{4}$ 5.0; $\mathrm{NH}_{4} \mathrm{NO}_{3}$ 2.0; $\mathrm{KH}_{2} \mathrm{PO}_{4}$ 2.0; $\mathrm{MgSO}_{4} \cdot 7 \mathrm{H}_{2} \mathrm{O}$ 0.2. Flasks containing $50 \mathrm{ml}$ of MSS medium were inoculated with a single colony from an agar plate. The effect of aeration on the bioemulsifier production was studied by incubating the cultures at $40^{\circ} \mathrm{C}$ under aerobic and anaerobic conditions at $120 \mathrm{rpm}$. Anaerobic cultures were prepared removing oxygen by aseptically bubbling oxygen-free nitrogen into the flasks, which were sealed with rubber stoppers. The ability of the strain to use hydrocarbons as the sole carbon source and the inductive effect of their presence on the bioemulsifier production were tested by growing the isolate in MSS medium with and without sucrose containing $5 \%(\mathrm{w} / \mathrm{v})$ of paraffin or crude oil. The paraffin used was viscous paraffin, purchased from Merck (Merck, Darmstadt, Germany). Crude oil was obtained from a Brazilian oil field [42].

Samples were taken at different time points during the fermentation to determine the biomass concentration and bioemulsifier production. Bacterial growth was determined by measuring the optical density at $600 \mathrm{~nm}$. Afterwards, the samples were centrifuged $(10,000 \times g, 20$ min, $20^{\circ} \mathrm{C}$ ) and cell-free supernatants were used to measure the surface tension and to determine the emulsifying activity, as described below. At the end of the fermentation, cells were harvested by centrifugation and the cell dry weight $(\mathrm{g} / \mathrm{l})$ was determined $\left(48 \mathrm{~h}\right.$ at $\left.105^{\circ} \mathrm{C}\right)$. To recover the bioemulsifier, the cell-free supernatants were mixed with three volumes of cold ethanol and incubated at $-20^{\circ} \mathrm{C}$ overnight. Afterwards, the precipitate was collected by centrifugation $(10,000 \times g, 20 \mathrm{~min}$, $\left.4^{\circ} \mathrm{C}\right)$. The crude bioemulsifier was dissolved in a minimal amount of demineralized water and freeze dried. The product obtained was weighed and stored at $-20^{\circ} \mathrm{C}$ for further use.

\section{Surface-activity determination}

Surface tension measurements of culture broth supernatants were performed according to the Ring method 
described elsewhere [43]. A KRÜSS K6 Tensiometer (KRÜSS GmbH, Hamburg, Germany) equipped with a $1.9 \mathrm{~cm}$ De Noüy platinum ring was used. To increase the accuracy of the surface tension measurements, an average of triplicates was conducted. All the measurements were performed at room temperature $\left(20^{\circ} \mathrm{C}\right)$.

\section{Emulsifying activity determination}

Emulsifying activity was determined by the addition of $2 \mathrm{ml}$ of $n$-hexadecane to the same volume of cell-free culture broth supernatants or bioemulsifier solutions in glass test tubes. The tubes were mixed with a vortex at high speed for $2 \mathrm{~min}$ and then were incubated at $40^{\circ} \mathrm{C}$ for $24 \mathrm{~h}$. The stability of the emulsion was determined after $24 \mathrm{~h}$, and the emulsification index $\left(E_{24}\right)$ was calculated as the percentage of the height of the emulsified layer $(\mathrm{mm})$ divided by the total height of the liquid column ( $\mathrm{mm}$ ). In order to study the ability of the bioemulsifier to form stable emulsions with different hydrophobic substrates, $n$ hexadecane was replaced in the emulsification assays by the following compounds: chloroform, crude oil, dichloromethane, ethyl acetate, gas oil, heating oil, $n$-hexane, liquid paraffin, toluene and xylene. All emulsification indexes were performed in triplicate.

\section{Effect of salinity, $\mathrm{pH}$ and temperature on bioemulsifier activity}

The effect of several environmental parameters on the activity of the bioemulsifier produced by the microbial isolate was determined. Stability studies were performed using bioemulsifier solutions prepared in distilled water at a concentration of $1 \mathrm{~g} / \mathrm{l}$. In order to assess the effect of salinity on the bioemulsifier activity, bioemulsifier solutions were supplemented with different $\mathrm{NaCl}$ concentrations (from 10 to $300 \mathrm{~g} / \mathrm{l}$ ) and the emulsifying activity was measured as described above. To evaluate the stability of the bioemulsifier at high temperatures, bioemulsifier solutions were incubated at $100^{\circ} \mathrm{C}$ for $1 \mathrm{~h}$ and at $121^{\circ} \mathrm{C}$ for $20 \mathrm{~min}$; the samples were then cooled to room temperature and the emulsification indexes were measured and compared to the corresponding values before heat treatment. The $\mathrm{pH}$ stability was studied by adjusting the bioemulsifier solutions to different $\mathrm{pH}$ values (2-13) using $\mathrm{HCl}$ or $\mathrm{NaOH}$ solutions, and then the emulsifying activity was measured as previously described. All the experiments were carried out in triplicate.

\section{Toxicity tests}

Toxicity tests were performed using the bioemulsifier produced by the isolate \#510 and three chemical SACs, namely Glucopone 650 (Fluka, Sigma-Aldrich), Fin$\operatorname{det}^{\circ} 1214 \mathrm{~N} / 23$ (Kao Corporation, Tokyo, Japan) and LAS (Kao Corporation, Tokyo, Japan). Microtox ${ }^{\bullet}$ assays were carried out according to the manufacturer's instructions. A $1000 \mathrm{mg} / \mathrm{l}$ starting solution (in distilled water) was prepared for each compound. Bioluminescence was measured in the Microtox ${ }^{\circ}$ M500 analyzer. The toxicity of the different SACs on the bioluminescent bacterium $V$. fisheri was evaluated by measuring the reduction of light emission by this microorganism when exposed to different concentrations of SACs for $30 \mathrm{~min}$ as compared to the control (distilled water). Whenever possible, the $\mathrm{EC}_{50}$ (effective concentration of the test substance that caused a 50\% reduction in the amount of luminescence emitted by the bacterial suspension after 30 min of exposure) was calculated.

\section{Biodegradability tests}

The biodegradability of the bioemulsifier produced by the isolate \#510 and the three chemical SACs in liquid medium was determined using respirometric tests. The Biochemical Oxygen Demand (BOD) was performed using $500 \mathrm{ml}$ respirometric bottles (OxiTop ${ }^{\circ}$ Respirometer System) which were filled with $250 \mathrm{ml}$ of the bioemulsifier $(1000 \mathrm{mg} / \mathrm{l})$ or the chemical SACs $(200 \mathrm{mg} / \mathrm{l})$ solutions along with $2 \mathrm{ml}$ of a soil bacteria inoculum $\left(\mathrm{OD}_{600}=1\right)$ obtained by adding $0.5 \mathrm{~g}$ of a soil sample to $50 \mathrm{ml}$ of rich medium. A control bottle (without SACs) was assembled to measure the basal activity. Bottles were incubated at $20^{\circ} \mathrm{C}$ for 5 days, and $\mathrm{BOD}_{5}$ was calculated by the difference between oxygen consumption in each bottle and the control. The Chemical Oxygen Demand (COD) was measured using a kit (Hach Company, USA) following the manufacturer's instructions.

\section{Bioemulsifier chemical characterization Extraction and purification}

The bioemulsifier was extracted from cell-free supernatants using the Folch extraction method that is commonly used to extract lipids from biomolecules. The Folch extraction procedure was performed as described elsewhere [44]. Briefly, a chloroform/methanol mixture $(2: 1)$ was added to the supernatant sample to a final chloroform/methanol/water ratio of 8:4:3. The mixture was centrifuged $(9000 \times g, 5 \mathrm{~min})$, the organic layer was collected and the samples were evaporated to dryness under $\mathrm{N}_{2}$ at $37^{\circ} \mathrm{C}$ for $30 \mathrm{~min}$. Prior to ${ }^{1} \mathrm{H}$ NMR spectroscopy analysis, the samples were re-dissolved in deuterated chloroform $\left(\mathrm{CDCl}_{3}\right)$.

\section{Fourier transform infrared spectroscopy (FT-IR) analysis}

The bioemulsifier recovered from the cell free supernatant was characterized by FT-IR. To perform the FT-IR assays, pellets were prepared by mixing $2 \mathrm{mg}$ of biosurfactant with $100 \mathrm{mg}$ of potassium bromide and pressing them at 9 metric tons for $3 \mathrm{~min}$. The pellet of biosurfactant was inserted in the FT-IR spectrometer and the respective 
infrared spectrum obtained. FT-IR spectra were collected on a Bruker Tensor 27 FT-IR spectrometer, using $\mathrm{KBr}$ pellets. Data were recorded at room temperature, in the range 4000 to $500 \mathrm{~cm}^{-1}$ by accumulating 64 scans with a resolution of $4 \mathrm{~cm}^{-1}$.

\section{Gel permeation chromatography (GPC) and sugars analysis}

The GPC analysis of the bioemulsifier, dissolved in ultra-pure water (HPLC for gradient analysis, ACROS Organics Chem. Co.) containing $0.1 \mathrm{M} \mathrm{NaNO}_{3}$ and $0.02 \% \mathrm{NaN}_{3}$ to a concentration of ca. $1.0 \%$, was carried out on a PL-GPC 110 system (Polymer Laboratories Ldt., UK) equipped with refraction index (RI) detector using two Plaquagel-OH MIXED $8 \mu \mathrm{m}$ columns $(300 \mathrm{~mm} \times$ $7.5 \mathrm{~mm}$ ) protected by Plaquagel $8 \mu \mathrm{m}$ guard pre-column (Polymer Laboratories Ltd., UK). The temperature of the injector and the columns was kept constant at $36^{\circ} \mathrm{C}$. The eluent, ultra-pure water containing $0.1 \mathrm{M} \mathrm{NaNO}_{3}$ and $0.02 \% \mathrm{NaN}_{3}$, was pumped at a flow rate of $0.9 \mathrm{ml} / \mathrm{min}$. The SEC columns were calibrated using pullulan standards (Polymer Laboratories Ldt., UK). The preliminary analysis on the sugar composition by acid methanolysis was carried out according to a previously published procedure [45].

\section{Nuclear Magnetic Resonance (NMR) spectroscopy}

${ }^{13} \mathrm{C}$ solid-state Cross Polarization-Magic Angle Spinning Nuclear Magnetic Resonance $\left({ }^{13} \mathrm{C}\right.$ CP-MAS NMR) spectra were recorded on a BrukerAvance 400 spectrometer operating at $100.6 \mathrm{MHz}(9.4 \mathrm{~T})$. Samples were spun in a zirconia's Bruker rotor at $7 \mathrm{kHz}$. Acquisition parameters were as follows: $90^{\circ}$ proton pulse of $4 \mu$ s width, contact time $2 \mathrm{~ms}$, and pulse delay of $4 \mathrm{~s}$. The ${ }^{1} \mathrm{H}$ NMR spectra of bioemulsifier soluble in $\mathrm{CDCl}_{3}$ were recorded at $25^{\circ} \mathrm{C}$ on a BrukerAvance 300 spectrometer operating at $300.13 \mathrm{MHz}$. Radio frequency was $90^{\circ}$ pulse, width of $10.2 \mu \mathrm{s}$, relaxation delay $12 \mathrm{~s}$, and 200-400 scans. The chemical shifts are reported relative to tetramethylsilane (TMS) used as an internal standard $(\delta=0.00)$.

\section{Competing interests}

The authors declare that they have no competing interests.

\section{Authors' contributions \\ All authors contributed to the design of the study. EJG isolated the bioemulsifier-producing strain, performed the studies related to bioemulsifier production and its functional characterization, and wrote part of the manuscript. JFBP, RC and DVE performed the studies related to the chemical characterization of the bioemulsifier and assisted in writing the manuscript. JAPC, JAT and LRR participated in the design of the study and drafted the manuscript. All authors read and approved the final manuscript.}

\section{Acknowledgements}

This work was supported by PARTEX OIL AND GAS. The authors thank the FCT Strategic Project PEst-OE/EQB/LA0023/2013. Jorge F. B. Pereira acknowledges the financial support from Fundação para a Ciência e a Tecnologia through doctoral research grant SFRH/BD/60228/2009.

\section{Author details}

'CEB - Centre of Biological Engineering, University of Minho, 4710-057 Braga, Portugal. ${ }^{2}$ CICECO - Chemistry Department, University of Aveiro, 3830-103 Aveiro, Portugal.

Received: 17 September 2014 Accepted: 19 January 2015 Published online: 31 January 2015

\section{References}

1. Banat IM, Franzetti A, Gandolfi I, Bestetti G, Martinotti MG, Fracchia L, et al. Microbial biosurfactants production, applications and future potential. Appl Microbiol Biotechnol. 2010;87:427-44.

2. Rosenberg E, Zuckerberg A, Rubinovitz C, Gutnick DL. Emulsifier of Arthrobacter RAG-1: isolation and emulsifying properties. Appl Environ Microbiol. 1979:37:402-8.

3. Navon-Venezia S, Zosim Z, Gottlieb A, Legmann R, Carmeli S, Ron E, et al. Alasan, a new bioemulsifier from Acinetobacter radioresistens. Appl Environ Microbiol. 1995;61:3240-4.

4. Ilori MO, Amobi CJ, Odocha AC. Factors affecting biosurfactant production by oil degrading Aeromonas spp. isolated from a tropical environment. Chemosphere. 2005;61:985-92.

5. Martínez-Checa F, Toledo FL, El Mabrouki K, Quesada E, Calvo C. Characteristics of bioemulsifier V2-7 synthesized in culture media added of hydrocarbons: chemical composition, emulsifying activity and rheological properties. Bioresour Technol. 2007;98:3130-5.

6. Dastgheib SMM, Amoozegar MA, Elahi E, Asad S, Banat IM. Bioemulsifier production by a halothermophilic Bacillus strain with potential applications in microbially enhanced oil recovery. Biotechnol Lett. 2008;30:263-70.

7. Franzetti A, Bestetti G, Caredda P, La Colla P, Tamburini E. Surface-active compounds and their role in the access to hydrocarbons in Gordonia strains. FEMS Microbiol Ecol. 2008;63:238-48.

8. Franzetti A, Gandolfi I, Raimondi C, Bestetti G, Banat IM, Smyth TJ, et al. Environmental fate, toxicity, characteristics and potential applications of novel bioemulsifiers produced by Variovorax paradoxus $7 \mathrm{bCT5}$. Bioresour Technol. 2012;108:245-51.

9. Zheng $C$, He J, Wang Y, Wang M, Huang Z. Hydrocarbon degradation and bioemulsifier production by thermophilic Geobacillus palidus strains. Bioresour Technol. 2011;102:9155-61.

10. Zheng C, Li Z, Su J, Zhang R, Liu C, Zhao M. Characterization and emulsifying property of a novel bioemulsifier by Aeribacillus pallidus YM-1. J Appl Microbiol. 2012;113:44-51.

11. de Sousa T, Bhosle S. Isolation and characterization of a lipopeptide bioemulsifier produced by Pseudomonas nitroreducens TSB.MJ10 isolated from a mangrove ecosystem. Bioresour Technol. 2012;123:256-62.

12. Monteiro AS, Coutinho JOPA, Ary C, Rosa CA, Siqueira EP, Santos VL. Characterization of new biosurfactant produced by Trychosporon montevidense CLOA72 isolated from dairy industry effluents. J Basic Microbiol. 2009:49:1-11.

13. Monteiro AS, Bonfim MRQ, Domingues VS, Corrêa A, Siqueira EP, Zani CL, et al. Identification and characterization of bioemulsifier-producing yeasts isolated from effluents of a dairy industry. Bioresour Technol. 2010;101:5186-93.

14. Monteiro AS, Domingues VS, Souza MV, Lula I, Gonçalves D, Siqueira EP, et al. Bioconversion of biodiesel refinery waste in the bioemulsifier by Trichosporon mycotoxinivorans CLA2. Biotechnol Biofuels. 2012;5:29.

15. Amaral PFF, Silva JM, Lehocky M, Barros-Timmons AMV, Coelho MAZ, Marrucho IM, et al. Production and characterization of a bioemulsifier from Yarrowia lipolytica. Process Biochem. 2006;41:1894-8.

16. Luna-Velasco MA, Esparza-García F, Cañizares-Villanueva RO, RodríguezVázquez R. Production and properties of a bioemulsifier synthesized by phenanthrene-degrading Penicillium sp. Process Biochem. 2007:42:310-4.

17. Vaz DA, Gudiña EJ, Alameda EJ, Teixeira JA, Rodrigues LR. Performance of a biosurfactant produced by a Bacillus subtilis strain isolated from crude oil samples as compared to commercial chemical surfactants. Colloids Surf B: Biointerfaces. 2012;89:167-74.

18. Pereira JFB, Gudiña EJ, Costa R, Vitorino R, Teixeira JA, Coutinho JAP, et al. Optimization and characterization of biosurfactant production by Bacillus subtilis isolates towards microbial enhanced oil recovery applications. Fuel. 2013;111:259-68

19. Cirigliano MC, Carman GM. Purification and characterization of liposan, a bioemulsifier from Candida lipolytica. Appl Environ Microbiol. 1985;50:846-50. 
20. Colin VL, Pereira CE, Villegas LB, Amoroso MJ, Abate CM. Production and partial characterization of bioemulsifier from a chromium-resistant actinobacteria. Chemosphere. 2013;90:1372-8.

21. Shete AM, Wadhawa G, Banat IM, Chopade BA. Mapping of patents on bioemulsifier and biosurfactant: a review. J Sci Ind Res. 2006;65:91-115.

22. Pacwa-Plociniczak M, Plaza GA, Piotrowska-Seget Z, Cameotra SS. Environmental applications of biosurfactants: recent advances. Int J Mol Sci. 2011;12:633-54.

23. Shavandi M, Mohebali G, Haddadi A, Shakarami H, Nuhi A. Emulsification potential of a newly isolated biosurfactant-producing bacterium, Rhodococcus sp. strain TA6. Colloids Surf B: Biointerfaces. 2011;82:477-82.

24. Najafi AR, Rahimpour MR, Jahanmiri AH, Roostaazad R, Arabian D, Soleimani $M$, et al. Interactive optimization of biosurfactant production by Paenibacillus alvei ARN63 isolated from an Iranian oil well. Colloids Surf B: Biointerfaces. 2011;82:33-9.

25. Khopade A, Biao R, Liu X, Mahadik K, Zhang L, Kokare C. Production and stability studies of the biosurfactant isolated from marine Nocardiopsis sp. B4. Desalination. 2012;285:198-204.

26. Toren A, Navon-Venezia S, Ron EZ, Rosenberg E. Emulsifying activities of purified alasan proteins from Acinetobacter radioresistens KA53. Appl Environ Microbiol. 2001;67:1102-6.

27. Vecino-Bello X, Devesa-Rey R, Cruz JM, Moldes AB. Study of the synergistic effects of salinity, $\mathrm{pH}$, and temperature on the surface-active properties of biosurfactants produced by Lactobacillus pentosus. J Agric Food Chem. 2012;60:1258-65

28. Ivshina IB, Kuyukina MS, Philp JC, Christofi N. Oil desorption from mineral and organic materials using biosurfactant complexes produced by Rhodococcus species. World J Microbiol Biotechnol. 1998;14:711-7.

29. Lima TMS, Procópio LC, Brandão FD, Leão BA, Tótola MR, Borges AC. Evaluation of bacterial surfactant toxicity towards petroleum degrading microorganisms. Bioresour Technol. 2011;102:2957-64.

30. Lima TMS, Procópio LC, Brandão FD, Carvalho AMX, Tótola MR, Borges AC. Biodegradability of bacterial surfactants. Biodegradation. 2011;22:585-92.

31. Mohan PK, Nakhla G, Yanful EK. Biokinetics of biodegradation of surfactants under aerobic, anoxic and anaerobic conditions. Water Res. 2006;40:533-40.

32. Chrzanowski L, Dziadas M, Lawniczak L, Cyplik P, Bialas W, Szulc A, et al. Biodegradation of rhamnolipids in liquid cultures: effect of biosurfactant dissipation on diesel fuel/B20 blend biodegradation efficiency and bacterial community composition. Bioresour Technol. 2012;111:328-35.

33. Frank $N$, Lißner A, Winkelmann M, Hüttl R, Mertens FO, Kaschabek SR, et al. Degradation of selected (bio-)surfactants by bacterial cultures monitored by calorimetric methods. Biodegradation. 2010;21:179-91.

34. Yim J, Kim SJ, Ahn SH, Lee HK. Characterization of a novel bioflocculant, p-KG03, from a marine dinoflagellate, Gyrodinium impudicum KG03. Bioresour Technol. 2007;98:361-7.

35. Fusconi R, Assunção RMN, Guimarães RM, Filho GR, Machado AEH. Exopolysaccharide produced by Gordonia polyisoprenivorans CCT 7137 in GYM commercial medium and sugarcane molasses alternative medium: FT-IR study and emulsifying activity. Carbohydr Polym. 2010;79:403-8.

36. Lopes MH, Neto CP, Barros AS, Rutledge D, Delgadillo I, Gil AM. Quantitation of aliphatic suberin in Quercus suber L. cork by FTIR spectroscopy and solid-state (13)C-NMR spectroscopy. Biopolymers. 2000;57:344-51.

37. Maunu SL. ${ }^{13} \mathrm{C}$ CP-MAS NMR studies of wood, cellulose fibers, and derivatives. In: Hu TQ, editor. Characterization of Lignocellulosic materials. Oxford: Blackwell Publishing Ltd; 2009. p. 148-70.

38. Balci M. Basic ${ }^{1} \mathrm{H}$ - and ${ }^{13} \mathrm{C}-\mathrm{NMR}$ spectroscopy. Oxford: Elsevier Science; 2005.

39. Bach $H$, Berdichevsky $Y$, Gutnick D. An exocellular protein from the oil-degrading microbe Acinetobacter venetianus RAG-1 enhances the emulsifying activity of the polymeric bioemulsifier emulsan. Appl Environ Microbiol. 2003:69:2608-15.

40. Kaplan N, Rosenberg E. Exopolysaccharide distribution and bioemulsifier production by Acinetobacter calcoaceticus BD4 and BD413. Appl Environ Microbiol. 1982;44:1335-41.

41. Moldes AB, Paradelo R, Vecino X, Cruz JM, Gudiña EJ, Rodrigues LR, et al Partial characterization of biosurfactant from Lactobacillus pentosus and comparison with sodium dodecyl sulphate for the bioremediation of hydrocarbon contaminated soil. BioMed Res Int. 2013; vol. 2013, Article ID 961842, doi:10.1155/2013/961842

42. Gudiña EJ, Pereira JFB, Costa R, Coutinho JAP, Teixeira JA, Rodrigues LR. Biosurfactant-producing and oil-degrading Bacillus subtilis strains enhance oil recovery in laboratory sand-packed columns. J Hazard Mater. 2013;261:106-13.

43. Gudiña EJ, Pereira JFB, Rodrigues LR, Coutinho JAP, Teixeira JA. Isolation and study of microorganisms from oil samples for application in microbial enhanced oil recovery. Int Biodeter Biodegrad. 2012;68:56-64.

44. Folch J, Lees M, Stanley GHS. A simple method for the Isolation and purification of total lipides from animal tissues. J Biol Chem. 1957;226:497-509.

45. Marques G, Gutiérrez A, del Rio JC, Evtuguin DV. Acetylated heteroxylan from Agave sisalana and its behaviour in alkaline pulping and TCF/ECF bleaching. Carbohydr Polym. 2010;81:517-23.

\section{Submit your next manuscript to BioMed Central and take full advantage of:}

- Convenient online submission

- Thorough peer review

- No space constraints or color figure charges

- Immediate publication on acceptance

- Inclusion in PubMed, CAS, Scopus and Google Scholar

- Research which is freely available for redistribution

Submit your manuscript at www.biomedcentral.com/submit
C) BioMed Central 